\title{
STATE LEVEL MECHANISMS FOR LEARNING FROM WHISTLEBLOWING CASES AT INSTITUTIONS OF HIGHER EDUCATION IN THE UNITED STATES
}

Christopher R. Schmidt

University of Pécs, Pécs, Hungary

E-mail: Schmidt.christopher@pte.hu

\begin{abstract}
State level mechanisms for soliciting, validating, and learning from whistleblower claims of fraud, theft, or misconduct against public colleges and universities are explored in four US states: California, Massachusetts, Michigan, and Ohio. Sequential public information requests were used to understand the methods that were used in each state, the types of claims that each state experienced, and to understand their processes for learning from such claims. The types of claims, breadth of scope that the claims span, and disposition of the claims is used to characterize each state's approach and compare and contrast results with other states in the sample. There was a wide variation in responses and approaches used in each state. Varying from no information solicited or maintained (Michigan) to full histories that include case level detail (Ohio), excellent multi-year case tracking and reporting (California) to the voluminous tracking of every property loss or damage in every institution (Massachusetts). An organic rubric is developed and used to compare and contrast the responses and service level provided by each of the states. Although anonymous whistleblower claims are essential to the governance and administration of higher education, state level mechanisms vary widely in their approaches to administering this process and ensuring better future outcomes. Establishing a standard based upon best practices would ensure that institutions are making the best use of all information available to them to improve their immunity from employee fraud and theft and misconduct.
\end{abstract}

Key words: internal controls, internal audit, higher education, whistleblowing, organizational learning, performance based funding, state administration of higher education.

\section{Introduction}

The processes for learning from whistleblower claims used in the state level administration of higher education funding in four US states are reviewed to identify the mechanisms that are used to learn from such claims. Each state is charged with administering and distributing taxpayer resources according to the best practicable and most efficient manner. These states provided $\$ 13.8$ Billion in state funds to institutions of higher education annually in 2013, according to the US Department of Education's Integrated Postsecondary Education Data System (IPEDS) database. Further, the institutions served 6.15 Million students and had cumulative annual revenues of $\$ 77.6$ Billion, which represented 24\% of the total revenue of all US higher education in 2013. (US Department of Education IPEDS database, 2013). 

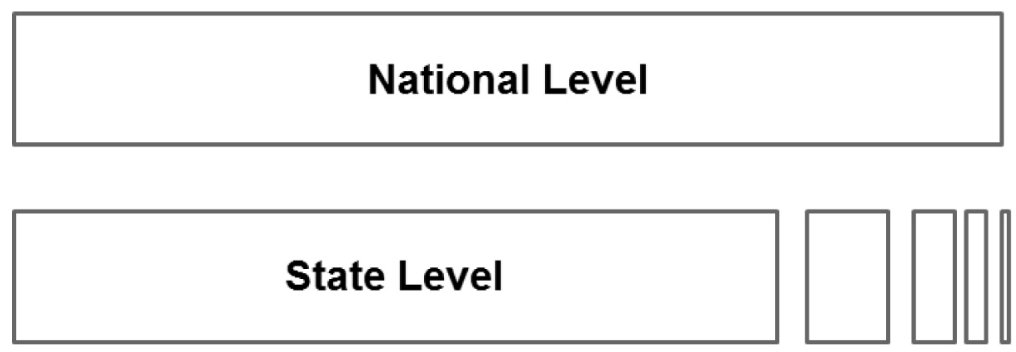

Institutional Level

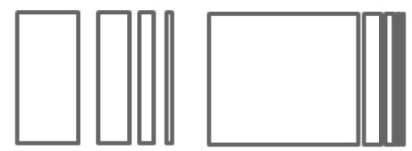

\section{Figure 1: Multiple Tiers of Administration of Higher Education title should be below.}

A key part of the function of disbursing funds is to maintain and monitor strong controls against fraud and theft. The Association of Certified Fraud Examiners (ACFE) in its annual report to nations (Ratley, 2014) states that $22 \%$ of the claims they looked at involved theft of over \$1million USD. An essential component of identifying fraud, theft, or misconduct of officials is the maintenance of a means to solicit and process claims made by concerned individuals, commonly referred to as whistleblowers. Fulfillment of these functions is shared through many functions over many layers of the state government and the approach to the distribution of these responsibilities varies by state.

Whistleblower claims involve accusations of fraud, theft, or misconduct of institution employees or leaders. Each of these accusations, whether valid or not, present a learning opportunity for the several levels of administration of higher education.

The functional areas of the institutions or governing bodies where the responsibility for administering whistleblowing or fraud reporting processes are faced with handling a large volume of claims, many of them groundless or trivial in nature. Although, only a small portion of all reported concerns results in actual findings of fraud, theft or ethics violations result in investigations, almost all of the claims provide important material to consider improving the operations and robustness of the institution.

\section{Problem of Research}

The existing literature, research, and subsequent legislation summarized below has focused on protecting and understanding the plight of the individual whistleblower, while comparatively little research has been conducted on the institutional learning processes and mechanisms to ensure the institution is maximizing learnings from such claims. Further, developing and improving mechanisms to learn from whistleblower claims is of growing importance as funding transitions from state to the student, as enrollments and funding is under pressure to be more efficient, and as the economic challenges of the 21 st century place pressure on individuals to adapt to slower growth or even deflation. A common misperception is that institutions of higher education are considered to be immune to employee fraud and theft, mainly based on the premise that these are knowledge-intensive institutions consisting of large pools of intellectuals, and ever striving for stronger knowledge processes (Dobrai \& Farkas, 2008).

Higher education in the US has faced several big financial challenges in the last decade. The recession of 2008 drove tremendous enrollment and revenue growth, which drove 
institutional expansion and pushed organizations to grow suddenly and without plan. These periods of rapid growth test an organization's ability to adhere to controls and, where controls are weak, an additional opportunity for fraud or theft is created. These periods of growth are often a central concern for auditors (Marquet 2011). In the subsequent years, 2012 to date, as the economic situation improved and as employment opportunities rebounded, and postrecession period student enrollments and revenue collapsed back to pre-recession levels, costsaving measures were sought to contract the organizations back to sustainable sizes. One of the largest and highest risk cost savings measures were focused on the hypothetical performance improvement that performance based funding schemes could deliver - funding institutions for graduations and completions as opposed to enrollments.

Incentive based, performance based funding may present an additional control risk in higher education, as evidenced by system-wide scandals at the primary education level in both Illinois (Levitt \& Dubner 2005) and Georgia (Carter 2015). Entire organizations of faculty and staff have been found to group-think themselves into manipulating measures and metrics to achieve personal gain at great cost to the students, the institutions they serve, their professions, and greater society. There is no evidence or mechanism to suggest that the scandals that have taken place in primary education cannot repeat themselves inside of an institution of higher education. In both the Illinois and Georgia cases, concerned teachers who reported the misconduct early on were dismissed and in some cases terminated, and only later were their concerns validated, after the scope and scale of the fraud reached massive and obvious scale.

Performance based funding in higher education has received renewed attention and focus with initiatives in many states being studied or implemented in recent years (Tanberg \& Hillman, 2014; Rutherford \& Rubovsky, 2014; Hillman, Tandberg, \& Fryer, 2015). Although this approach may be wholly incompatible with the premise of higher education, the application of private sector competitive incentive metrics and management theory to higher education is a recurring theme. Much as antibiotics are regularly incorrectly prescribed by physicians to help treat the common cold or other viral infections, to appease the patient, politicians are motivated to connect college and university funding to student success rates. Performance based funding takes many forms, but essential attempt to connect funding levels with student success. The definition of student success is a field of study in its own right.

Simultaneously, further contributing to the risk environment in higher education is the deterioration of traditional controls such as a vibrant mass media, such as newspapers and investigative journalism. The impact of the internet and transition of the population's away from traditional media sources, such as printed press and radio broadcast and broadcast television toward self-directed on-demand internet has constrained the financing of traditional investigative journalism. According to the Newspaper Association of America and Weissman (2014), the traditional means for uncovering large fraud and theft schemes in public services, weakened to a point that has reduced the size of the press to pre-WWII levels of revenue and circulation. The impact of this is studied by Aucion (2005) and further by Houston (2010) and how traditional investigative journalism has transformed into more activity on the internet, and the impact of the larger scattered sources and uptake by the larger populations is limited by their own personal tastes and self-directed consumption.

The term "whistleblowing" has its origins in a 1972 conference paper by the famous American activist Ralph Nader (Nader, Petkas \& Blackwell, 1972). The importance of the more general function of internal controls in the public sector and specifically Higher Education to ensure that abuses and misconduct are prevented are the focus of Dr. Joe Christopher's publications in Australia contribute to the search to improve control over spending while reducing operating costs by sharing among institutions. Christopher (2014) looked specifically at the case of Australia and in a survey of Chief Audit Executives of the 37 universities, concluded that "flexible" arrangements had been made in implementing best practice internal controls and that these compromises, along with incomplete legislation and policies, lead to a number of opportunities to improve and strengthen controls against fraud and theft. Schmidt and 
Christopher R. SCHMIDT. State level mechanisms for learning from whistleblowing cases at institutions of higher education in the United States

PROBLEMS

OF MANAGEMENT

IN THE $21^{\text {st }}$ CENTURY Vol. 11, No. 1, 2016

Kiraly (2015) developed a rubric to compare and contrast the use of Internet Communications Technology to solicit and report on both whistleblower claims and how institutions in Hungary and the United States publicly prioritized learning and improving the institutions immunity from such claims.

Janet Near and Marcia Miceli, thought leaders in the area of whistleblowing with over 50 unique research papers and publications on the topic, in their paper "Effective Whistleblowing" (1995) studied whistleblowing from the perspective of the risks to the individual making the claim, at which time several extreme instances of retaliation had been exposed. This included an analysis of legislation that protected whistleblowers specific to the origination of the complaint. If the complaint was made via internal or external channels the legislated protections varied, with some states protecting only individuals that engaged through internal channels. They found that of cases reported to the dept. of agriculture that $70 \%$ of the claims were made by public sector employees, although public sector employment made up only $20 \%$ of all employment, concluding that public sector employees are more likely to blow the whistle. Further, Near and Miceli explore the relationship between the likelihood of someone blowing the whistle and the individual's confidence that their action will successfully bring an end to the abuse or misconduct. In this paper, they concluded that people who were blowing the whistle were not "crackpots". They also explored the likelihood of retaliation and the dependency on individual personality and organizational structure, and called for more research on the topic (1995).

Legislation governing the treatment and protection of the individual whistleblower was solidified in the passage of the Whistleblower Protection Act of 1989 for federal employees was enhanced in 2012 with the purpose of enhancing coverage beyond federal employees and bringing it into the jurisdiction of the Securities Exchange Commission. Additionally, the US Dept. of Labor, and its Occupational Health and Safety Administration (OSHA) have extensive programs to educate and inform the workforce of their rights and proper process regarding whistleblower.

Internal Controls and their significance in preventing the misuse or misappropriation of assets is a topic that is well ingrained in financial management of publicly listed for-profit corporations and is based in the significance of the importance of the accurate recording and reporting of activities of a corporation via annual audited financial statements, in order to ensure investors are aware of the performance of the organization (Doyle, Ge, \& McVay, 2006).

Daniel Arce, in his 2009 paper, presents models based on game theory that lead him to the conclusion that the whistleblowing protections included in the Sarbanes-Oxley Act are insufficient in providing incentives for individuals to expose wrongdoing. Arce cited Bowie (1982) and Jubb (1999) as the sources for his definition of Whistleblowing and elaborates on the expectations and conviction that is symptomatic of a whistleblower as they are preparing for the act of exposing what they believe to be wrongdoing. Motivation for Arce's paper was the 2002 Time magazine citation of persons of the year being three whistleblowers: Cynthia Cooper (WorldCom), Coleen Rowley (the FBI) and Sherron Watkins (Enron). Whistleblower protections are now included into the framework of Corporate Social Responsibility (Vandekerckhove, 2006).

\section{Research Focus}

This research explores and catalogues the various mechanisms used at a sample of states used to solicit, validate, and process concerns of fraud theft, or misconduct of employees of state owned institutions of higher education (colleges and universities) and expands on a field study performed in Ohio (Schmidt 2015) to include the states of Michigan, California, and Massachusetts. The research was initiated upon the assumption that consistent processes existed and were employed at the state level and would in all cases be able to present data that could be used to document the nature of claims and explore institutional learning mechanisms. As presented below this was not the case. Even where this research approach was able to produced 
Christopher R. SCHMIDT. State level mechanisms for learning from whistleblowing cases at institutions of higher education in the United States

data on specific claims, there was significant variation in the level of detail available to warrant an important discussion of the processes employed. Where the approach did not work well, processes did either not exist or occurred at a very high level of abstraction, warranting an even deeper exploration and discussion focusing on the disparity of approaches used.

\section{$\bigcirc$ Actual Claims Institutional Methods State Methods}

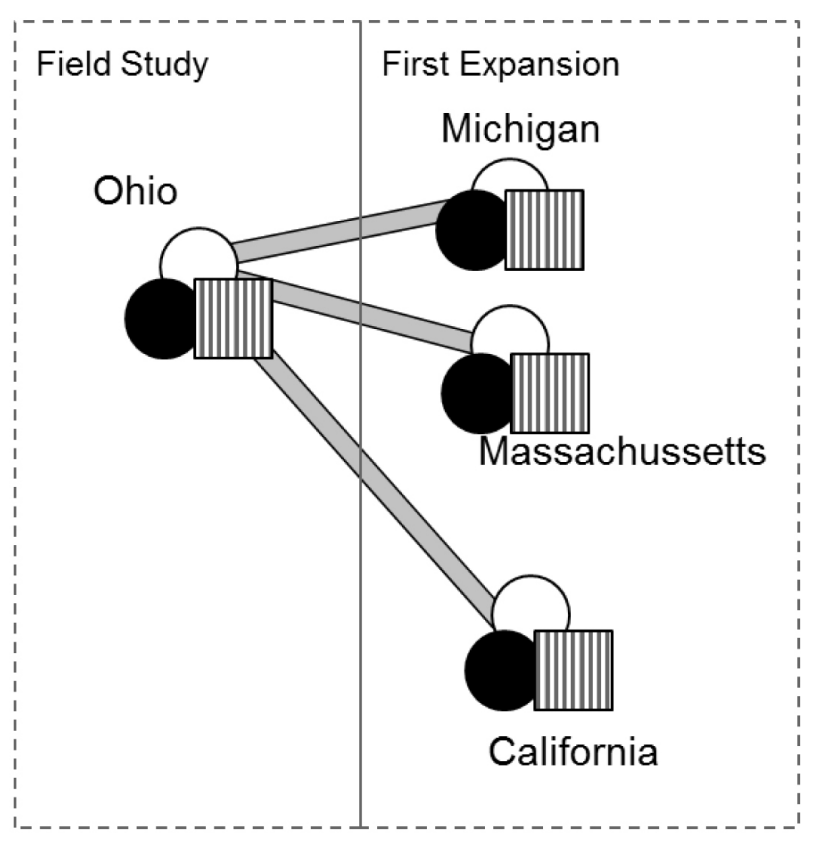

Figure 2: Overview of research.

The analysis of the variation in the responses obtained from the states led to the development of a rubric by which to compare the results and contrast the approaches taken to soliciting, administering, and learning from whistleblowing complaints. The origins of the variation in the mechanisms of organizational learning observed was then discussed in terms of causal factors such as the historical evolution of state law and policy, with regards to whistleblowing claims. By cataloguing and describing both the actual claims filed by whistleblower, and studying the state processes used to solicit, validate, and process these claims of fraud or theft, this paper will show that there is a wide spectrum of practices and treatments between states in the way they approach soliciting, enabling claims to be made, their approaches to the validation, and processing of the claims.

\section{Methodology of Research}

\section{General Background of Research}

Sequential public information requests were used to obtain information from state level organizations that were responsible for administering the fraud process in the respective states. The same public information requests were sent to each state auditor's office. The initial request was for a listing of claims received against institutions of higher education. This listing of recorded complaints was reviewed, where available, and a list of specific claims was used in a second request for information to receive internal documents that may reveal more specifics about the nature of the claims, and actual internal disposition that was taken in each case. Only the State of Ohio responded with additional case level details such as working papers and investigators reports. 
Christopher R. SCHMIDT. State level mechanisms for learning from whistleblowing cases at institutions of higher education in the United States

$\begin{array}{r}\text { OF MANAGEMENT } \\ \text { IN THE } 21^{\text {st }} \text { CENTURY } \\ \text { Vol. 11, No. 1, } 2016 \\ \hline 48\end{array}$

\section{Sample of Research}

This research focuses on state funded institutions of higher education, which form about $80 \%$ of the total enrollment of students in the United States as of 2010 (US Census Bureau), which is a declining portion of all enrollment, as private institutions focused on distant learning gain huge enrollment. Ohio was taken as the field study data source given the authors familiarity with the state. Subsequent states were added sequentially until a variety of outcomes were welldocumented and provided sufficient evidence of variation in approaches. Massachusetts and then California were chosen for their concentration of prestigious educational institutions with global recognition. Michigan was chosen again due to the prestigious academic stature of its flagship institutions, the University of Michigan and Michigan Technological University.

\section{Instrument and Procedures}

The quantification of the differences and points of variation between the responses facilitated the development of the rubric included in the table below as a basis for consistent analysis and evaluation of the responses received from each of the states. Seven control points described in Table 1 address the processes used, while three additional points address the nature of the complaints received.

\section{Table 1. Key points of the administration of whistleblowing claims.}

\begin{tabular}{|c|c|c|}
\hline & Control Point & Point of Inquiry \\
\hline 1 & Solicit and collect whistleblower claims & $\begin{array}{l}\text { Does the state solicit and log whistleblower complaints specific } \\
\text { to higher education? }\end{array}$ \\
\hline 2 & Log of claims available via public records request & Is the log of complaints available to the public? \\
\hline 3 & $\begin{array}{l}\text { Follow-up and investigation details available via } \\
\text { public records request }\end{array}$ & Are investigative reports and work papers available for review? \\
\hline 4 & Reporting of findings available to public & Is a report of the findings for each claim available to the public? \\
\hline 5 & $\begin{array}{l}\text { Track issues to resolution and completion (multi- } \\
\text { year) }\end{array}$ & \multirow{4}{*}{$\begin{array}{l}\text { - Is there a summary report at year-end, that provides status on } \\
\text { open and unresolved issues year-to-year? } \\
\text { Is there an analysis of findings and effort to manage the insti- } \\
\text { tutions more effectively and to protect the institutions from a } \\
\text { recurrence? } \\
\text { Is there an estimate of the financial or reputational impact that } \\
\text { such a claim can have? }\end{array}$} \\
\hline 6 & $\begin{array}{l}\text { Evidence of learning and improved immunity to } \\
\text { internal fraud/theft/misconduct }\end{array}$ & \\
\hline 7 & Estimates of potential loss & \\
\hline & Nature of Claims and Findings & \\
\hline 8 & Volume & $\begin{array}{l}\text { Is the volume of complaints or cases recorded comparatively } \\
\text { high or low? }\end{array}$ \\
\hline 9 & Materiality & $\begin{array}{l}\text { Is the estimated monetary impact of the average claim com- } \\
\text { paratively high or low? }\end{array}$ \\
\hline 10 & Subject of Claim & Fraud, Theft, Misconduct \\
\hline
\end{tabular}

The rubric facilitates consistent analysis and evaluation of the responses received from each of the states and summarizes the key control points that are measurable and indicate the quality and strength of the processes implemented by each state.

Data Analysis

Ohio

Ohio is one of the top 10 states ranked by GDP which exceeded $\$ 580$ billion USD in 2015. (Ohio Development Services Agency, Economic Overview, 2016) 26 public universities 
and colleges with an enrollment of 937,000 in 2013 and receive approximately $\$ 1.85$ Billion in state funding annually, representing approximately $15 \%$ of the total college and university annual revenue of $\$ 12.5$ Billion. (US Department of Education, IPEDS database, 2013)

In a conference paper and subsequent publication (Schmidt \& Farkas 2015; Schmidt 2015) analyzed claims made in the state of Ohio using a publicly available data source. The dataset that was used for the initial part of this research was comprised of fraud ethics claims logged by the Ohio Auditor of State, and the dataset spans 28 months, starting in May 2012 and ending September 2014. This data was provided by the Ohio Auditor of State's open government unit, and the data is available online at https://ohioauditor.gov/fraud/.

They found that of the 1,386 claims made to the Ohio Auditor of State during the period under study, as categorized by the Auditor's Office, twelve claims, or approximately $1 \%$ of all fraud claims made during the period, were filed against public institutions of higher education. Complaints are always assumed to be unsubstantiated until evidence is found to support the claim. The Ohio Auditor of State's work papers and findings document their efforts to investigate these claims and record their findings via summary track sheets that this paper analyzed to interpret the nature of the claims and to determine which actions, if any, were taken by the state or institution.

This dataset includes claims for all public institutions funded by the state of Ohio including in addition to universities and colleges, prisons, the elementary educational school system, and all other state governmental bodies. The data was filtered by description of the institution and only claims specific to universities and colleges were extracted and used for the purpose of this study. The resulting selected dataset for this study represents only twelve claims and less than $1 \%$ of all claims received by the state of Ohio in the time frame under consideration.

In order to further research the details of each of the twelve claims identified above, additional public record requests were made to the auditor of state, requesting copies of all work papers and any generated work products, such as findings summaries or reports. These work papers and reports were provided by the Auditor of State for all of claims under review. The actual work papers provided to the researcher consisted of varying levels of detail and complexity based on the nature of each case and the severity and validity of each claim. The work papers for these twelve claims made against institutions of higher education and each made in areas of importance, areas where real concerns exist regarding the potential for an ethical breach, only three of the claims revealed instances of genuine fraud or theft that merited action by the State and the institution involved.

To extend the analysis, these claims have been sorted according to whether work papers and summary findings suggest to a qualified auditor that an extended investigation could potentially uncover a valid complaint. Table 2 summarizes these "actionable complaints" by which internal process they fall within. Further, if the Auditor of State did indeed investigate a claim and found action warranted, these claims are recorded as "action taken" in the Table below. 
Christopher R. SCHMIDT. State level mechanisms for learning from whistleblowing cases at institutions of higher education in the United States

OF MANAGEMENT

IN THE $21^{\text {st }}$ CENTURY Vol. 11, No. 1, 2016

Table 2. Summary of Ohio claims and outcomes.

\begin{tabular}{lllll}
\hline Fraud Complaints Received by the Ohio Auditor of State between May 2012 and Sept 2014 & \\
\hline Internal Process & $\begin{array}{l}\text { Number of } \\
\text { Complaints }\end{array}$ & $\begin{array}{l}\text { Number of } \\
\text { Actionable } \\
\text { Complaints }\end{array}$ & $\begin{array}{l}\text { Action } \\
\text { Taken }\end{array}$ & $\begin{array}{l}\text { Action } \\
\text { Not Taken }\end{array}$ \\
\hline Human Resources - Hiring and Compensation & 4 & 2 & 1 & 1 \\
Theft or Misappropriation of Institutional Assets & 4 & 2 & 2 & 0 \\
Theft or Misappropriation of Student Funds & 3 & 0 & 0 & 0 \\
Unethical or Fraudulent Institution & 1 & 0 & 0 & 0 \\
\hline Total All Claims & 12 & 4 & 3 & 1 \\
\hline
\end{tabular}

Source: Schmidt (2015)

The difference between "actionable" and "action taken" lies in whether or not the institution pursued an opportunity to improve internal processes. Failure to complete this part of the process is often due to internal resource limitations or policies. In the cases analyzed here, the Auditor of State was focusing solely on the traditional topics of the classical scope of vouching and validating the accuracy of financial statements, and of identifying fraud and theft.

Massachusetts

Massachusetts is one of the geographically smallest states in the US, and with a population of 6.7 million has a disproportionately high number of prestigious institutions of higher education - 122 based on the state's department of higher education (Galvin, 2015) This includes Harvard, MIT, Boston College, Brandeis University, Boston University, Williams College, Amherst College, and the University of Massachusetts and had an enrollment of 665,000 students in 2013. In the same year, according to the US Dept. of Education IPEDS database, the state of Massachusetts funded \$1.2 Billion of the \$4.8 Billion in total revenue of these institutions. (US Department of Education, IPEDS database, 2013)

In early spring 2015 the initial request for data was sent to the Auditor of State's office, who replied promptly and provided an exhaustive database of claims tracked by the auditor's office. This response cited Chapter 647 of the Acts of 1989, which is Massachusetts' statute on Internal Control and the requirement to maintain records of events.

The Massachusetts auditor returned 69 pages containing 380 individual complaints or whistleblower reports, received between January 1, 2010 and March 25th, 2015. While numerically the majority of these items tracked involved theft reports of physical assets, mostly computers or portable assets, or cash in estimated loss dollar values below $\$ 1,000,24$ fund thefts or acts of embezzlement were reported that totaled over $\$ 4$ Mil, of which one fraud scheme totaled $\$ 3.8 \mathrm{Mil}$. Table 3 summarizes these findings and uses the categorizations provided by the auditor to provide some insight into the nature of the claims that were tracked by the state. 
Table 3. Claims made against institutions of higher education - Massachusetts.

\begin{tabular}{lllll}
\hline \multicolumn{4}{l}{ Fraud Complaints Received by the Massachusetts Auditor of State between January 2010 and March $\mathbf{2 0 1 5}$} \\
\hline Type of Loss & Incidents & Estimated Loss & $\begin{array}{l}\text { Percent of } \\
\text { Incidents }\end{array}$ & $\begin{array}{l}\text { Percent of } \\
\text { Loss }\end{array}$ \\
\hline Theft, property & 301 & $\$ 451,500$ & $79.2 \%$ & $10.2 \%$ \\
Theft, cash & 30 & $\$ 15,000$ & $7.9 \%$ & $0.3 \%$ \\
Theft, fund & 24 & $\$ 3,966,200$ & $6.3 \%$ & $89.2 \%$ \\
Miscellaneous & 15 & $\$ 7,500$ & $3.9 \%$ & $0.2 \%$ \\
Vandalism & 10 & $\$ 5,000$ & $2.6 \%$ & $0.1 \%$ \\
\hline Total All Claims & $\mathbf{3 8 0}$ & $\$ \mathbf{4 , 4 4 5 , 2 0 0}$ & $\mathbf{1 0 0 \%}$ & $\mathbf{1 0 0 \%}$ \\
\hline
\end{tabular}

The factor that is unique about Massachusetts and dramatically increases the number of claims, is the requirement of institutions to report losses to the state. While the results of this legal framework is that there is a much higher number of claims being tracked and reviewed for higher education in Massachusetts, the inclusion of campus related thefts and vandalism, by nature relatively low complexity and value, and relevant to the topic of strong internal controls, obfuscates the analysis and visibility to more difficult topics such as employee theft of funds or other types of fraud or misconduct.

Upon requesting details from the auditor for 12 of the potentially most significant claims, the auditor responded that only one audit report was available, specific to the Maritime Academy and some controls over payroll and ethics of an instructor who was apparently working in a competitive private position while also being employed by the state. The estimated value of the fraud was $\$ 50,000$.

The largest fraud tracked in this report, $\$ 3.8$ Million, which makes up the majority of the value reported to have been tracked by the state, was uncovered only after the employee's death. The scheme was complex fraud scheme perpetrated by a single administrative employee with access and ability to manipulate and defraud without detection. The auditor has not as yet provided a report on this incident. This case emphasizes the importance and also the limitations of internal control and whistleblowing, and shows a clear difference between, informal everyday crimes of theft of property and its sophisticated relatives: embezzlement and more sophisticated theft schemes.

\section{Michigan}

The state of Michigan with a population of 9.9 million, 93 institutions of higher education of which 15 public four year and 29 public two-year colleges with enrollment of 683,000 students. (Michigan Department of Energy, Labor and Economic Growth, Directory of Michigan Institutions of Higher Education, 2011) The US Dept. of Education's IPEDS database shows that for 2013 the state of Michigan provided \$1.6 of the \$14.8 Billion in total revenue of its colleges and universities. (US Department of Education, IPEDS database, 2013)

The Michigan Auditor General was sent the same request for information as California, Ohio, and Massachusetts, and the response received, was that, at the state level, no solicitation or reporting was performed, and that this was the responsibility of each institution.

Michigan exemplifies the decentralized approach to control management and somewhat the other end of the spectrum when compared to Ohio and Massachusetts. The Auditor General stated that the boards of each of the respective colleges and universities were responsible for administering their own internal controls. 
Christopher R. SCHMIDT. State level mechanisms for learning from whistleblowing cases at institutions of higher education in the United States

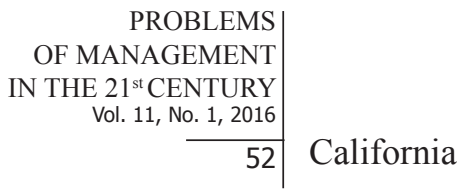

The state of California with a population of 38 million, with 789 institutions of higher education, serving 1.8 Million students. According to the US Dept. of Education's IPEDS database, in 2013 California's universities and colleges had enrollments of 3.7 Million, and the state funded $\$ 8.9$ of $\$ 45$ Billion in total revenue for that year. (US Department of Education, IPEDS database, 2013) This represents over half of all of the value covered by this study and over $14 \%$ of the total US spend on higher education.

The California Auditor of State was sent the request for information and responded with copies of the annual report of accusations of fraud and theft by employees entitled "Investigations of Improper Activities by State Agencies and Employees" which is produced annually as a report to the Governor and State Legislature and is available online for all citizens to review.

The Investigation reports were reviewed for the years under study 2010-2014 and only one issue was found to be related to higher education. The bureau of the state auditor received approximately 5,000 allegations of improper governmental activities annually, which required it to determine whether the allegations involved improprieties by state agencies or employees. In response to the allegations, the bureau opened approximately 1,000 new cases annually, and it reviewed or continued to work on 1-200 unsolved cases it opened previously. For these approximately 1,200 cases, the bureau completed a preliminary review process and determined the cases that lacked sufficient information for an investigation. The bureau also referred cases to other state agencies for action and-either independently or with assistance from other state agencies - conducted investigations of cases. The annual report details the results of 11 particularly significant investigations completed by the bureau or undertaken jointly by the bureau and other state agencies.

Notable was the fact that issues, once identified, were carried forward into the next year's report until resolution of the investigation was completed. California's processes for tracking and reporting issues are best-practice, being the only state that monitored issues through resolution in their reporting. Additionally, the fully online availability of the reports was also unique and best-practice.

\section{Results of Research}

Reviewing the responses and materials, provided by each of the four states considered in this study, provides a basis for comparison and clearly shows differences in approaches, types of claims reported, and varied levels of tracking, reporting, and public presentation. To facilitate that comparison, the table below lists the key points that became apparent throughout the process of requesting and analyzing the public records provided.

Looking at each of the criteria listed in table 4 , where the findings are presented, the key control points for discussion arose in the analysis of the findings. With regard to the process for soliciting and collecting whistleblower claims, the majority of states solicited claims, not all did. The outlier in this process was the state of Michigan which had no mechanism or processes in place at the state level to solicit or process or learn from whistleblower claims. 
Table 4. Assessment of Multi-State survey of administration of whistleblowing claims.

\begin{tabular}{|c|c|c|c|c|c|}
\hline & \multicolumn{5}{|l|}{ Key points comparing responses between states } \\
\hline & Control Point & California & Massachusetts & Michigan & Ohio \\
\hline 1 & Solicit and collect whistleblower claims & YES & YES & NO & YES \\
\hline 2 & Log of claims available via public records request & YES & YES & NO & YES \\
\hline 3 & $\begin{array}{l}\text { Follow-up and investigation details available via } \\
\text { public records request }\end{array}$ & NO & NO & NO & YES \\
\hline 4 & Reporting of findings available to public & YES & YES & NO & YES \\
\hline 5 & $\begin{array}{l}\text { Track issues to resolution and completion (multi- } \\
\text { year) }\end{array}$ & YES & NO & NO & NO \\
\hline 6 & $\begin{array}{l}\text { Evidence of learning and improved immunity to } \\
\text { internal fraud/theft/misconduct }\end{array}$ & NO & NO & NO & NO \\
\hline 7 & Estimates of potential loss & NO & YES & NO & NO \\
\hline & Nature of Claims and Findings & & & & \\
\hline 8 & Volume & Low & High & None & Low \\
\hline 9 & Materiality & High & Low & None & High \\
\hline 10 & Subject of Claims & Theft & Theft & None & $\begin{array}{l}\text { Misconduct, } \\
\text { Fraud, Theft }\end{array}$ \\
\hline
\end{tabular}

Further, the process for logging the claims received and monitoring the status of the claim were sometimes, but not always available via public records request. Ohio had the most easily accessible log of claims that can be accessed from their public facing internet website. Massachusetts provided a database of claim reports upon request, and California had only references to their online annual summary of findings. Logging claims and making them available to the public and stakeholders, while preserving the anonymity of the claimant, is the best practice demonstrated by Ohio.

\section{Discussion}

The process of investigating claims and recording details in ways that allow materials to be made available via public records request was only observed in the state of Ohio. Ohio provided a number of internal documents for each case that were able to preserve the confidentiality of the whistleblower where possible, and allowed an external third party to understand more details of the nature of the claim and to understand the investigative undertakings used to better understand and prove or disprove the claim. Massachusetts produced only one report of investigative findings which was available through their public website related to an issue at a trade school, although their count of issues included in their database was the highest of all states responses. Additionally, the largest claim included in the whistleblower claim database was actually the documentation of a reported embezzlement scheme post-mortem, following the death of the perpetrator. California provided summary level detail about high level claims against its institutions which provide for a good understanding of a small number of select claims, but does not allow the public and stakeholders to review smaller, not selected claims, if they existed.

With regards to providing a summarization of the year's activities and providing stakeholders with an analysis of the types of claims received, notable high profile or high impact cases, and the resolution status on longer-term investigations is an important component of the effective management of these claims, and enables long-term learning and improvement. California was the only state that not only made the additional effort to summarize their annual findings in a report to their legislature and stakeholders, but also made this report available online for transparent access. 
Christopher R. SCHMIDT. State level mechanisms for learning from whistleblowing cases at institutions of higher education in the United States

PROBLEMS

OF MANAGEMENT

IN THE $21^{\text {st }}$ CENTURY

Vol. 11 , No. 1, 2016

The process of tracking and monitoring issues to resolution and completion over longer, multi-year time frames, is essential for government to sustain longer term, bigger scale investigations. The states of Ohio and California provided some evidence that claims were investigated, and that evidence was available either on-demand via their public website or through public records request. With California's annual report example, salient cases were able to be shared and disseminated to a wider audience, and issues that were unresolved over multiple years were not lost or forgotten, but rather were carried forward in each subsequent year's report of findings.

In looking for evidence of learning and improved immunity to internal fraud/theft/ misconduct that was undertaken by the state or the universities or colleges involved in the claims, no publicly available information was found in any of the states. In no case, was there any evidence that the governing bodies were able to learn and improve their immunity to these internal fraud, theft, and misconduct issues. California, in summarizing findings in a report that was then published on their public website, provided a mechanism for the institutions and governing bodies to become aware of the issues in other organizations and raise the awareness across all institutions and stakeholders. This expands upon the finding of Schmidt and Kiraly (2015) who found little evidence that institutions in Hungary and the United States publicly prioritized learning and improving the institutions' immunity from such claims via their strategic planning processes.

Categorizing the claims, received from the state by the nature of the subject that they are addressing, identifies substantial disparity in the nature of the claims and the types of processes or losses and risks identified by state. Each state that did solicit and log claims and a variation in the types of claims resulted in a larger or smaller volume of claims being tracked. Whereas, Ohio received claims that involved a range of administrative and operational processes in the institution, in Massachusetts where legislation mandated the inclusion of the losses or damage to all state property, the sheer volume of claims was overwhelming, and in fact no claims of other nature were recorded in Massachusetts. This raises the question of if this type of legislation and mandate simply adds noise to drown out and cover up other larger issues.

\section{Conclusions}

This research outlines a framework for institutions to pro-actively identify and learn from whistleblower claims in order to reduce occurrences, shorten response times, and improve transparency and extends the work of Janet Near and Marcia Miceli, which focused on protecting the whistleblower post-incident. The research established a rubric to facilitate the analysis and comparison of the processes employed via key control points, which was applied to the data and responses from each of the states included in the study. In line with findings from Joe Christopher, which focus on internal controls at universities in Australia, the findings from this investigation of four US states show that there is wide variation in practice, focus, and transparency generated by the processes used in these states to administer claims of fraud, theft, and misconduct reported via whistleblower complaints. The variation in responses and approaches used in each state ranged from no information solicited or maintained (Michigan) to full histories that include case level detail (Ohio), excellent multi-year case tracking and reporting (California) to the voluminous tracking of every property loss or damage in every institution (Massachusetts). Additionally, no evidence was found of well-considered and executed mechanisms to show improvement and learning from such claims. This may have been a result of both legislative history and a focus on enforcement and the punishment of perpetrators. Although anonymous "whistleblower" claims are essential to the governance and administration of higher education, state level mechanisms vary widely in their approaches to administering this process and ensuring better future outcomes. 
Covering approximately $24 \%$ of all higher education spending in the US, expansion of the study to include more states may identify both more variation in approaches and outcomes, as well as additional best-practices that could be incorporated into the establishment of a standard approach. Further, an international comparative study of national practices may identify systems and nations, who may have been more successful at orchestrating a consistent policy and practice for improving the institution through responding to these valuable data points that the claims constitute. It is recommended that future efforts focus on outlining a path of incorporating the best practices outlined in this research into standards for socially responsible governance in order to improve the likelihood of structured learning from whistleblower claims in order to pro-actively protect individuals and the institution from employee fraud and theft and misconduct.

\section{References}

Arce, D. G. (2010). Corporate virtue: Treatment of whistleblowers and the punishment of violators. European Journal of Political Economy, 26 (3), 363-371.

Aucion, J. (2005). The evolution of American investigative journalism. Columbia, Missouri: University of Missouri Press.

Carter, C. J. (2013). Grand jury indicts 35 in Georgia school cheating scandal [online news article]. Retrieved from http://www.cnn.com/2013/03/29/us/georgia-cheating-scandal/ on April 23, 2015.

Christopher, J. (2014). Internal audit: Does it enhance governance in the Australian public university sector? Educational Management Administration \& Leadership, 43 (6), 1-18. doi: $10.1177 / 1741143214543206$.

Dobrai, K., \& Farkas, F. (2008). Knowledge-based services: Examining knowledge processes in publicserving nonprofit organizations. International Journal of Knowledge and Culture Change Management, 8 (2), 9-21.

Doyle, J., Ge, W., \& McVay, S. (2006). Determinants of weaknesses in internal control over financial reporting. Journal of Accounting and Economics, 44 (1), 193-223.

Galvin, W. F. (2015). Welcome to Massachusetts: A Primer on Bay State Basics [electronic promotional, informational pamphlet]. Retrieved from http://www.sec.state.ma.us/cis/cispdf/Welcome_to_ Mass.pdf on July 10, 2015.

Hillman, N. W., Tandberg, D. A., \& Fryar, A. H. (2015). Evaluating the impacts of 'new' performance funding in higher education. Educational Evaluation and Policy Analysis, 1-19. doi: $10.3102 / 0162373714560224$.

Houston, B. (2010). The future of investigative journalism. Daedalus, 139 (2), 45-56.

Levitt, S. D., \& Dubner, S. J. (2005). Freakonomics: A Rogue economist explains the hidden side of everything. New York: Harper Collins.

Marquet, Christopher T. (2011). Embezzlement epidemic. University Business, 14 (7), 89-94.

Michigan Department of Energy, Labor and Economic Growth. (2011). Directory of Michigan Institutions of Higher Education, 2011. Retrieved from http://www.michigan.gov/documents/mdcd/20102011_Higher_Education_Directory_342472_7.pdf on December 31, 2014.

Nader, R., Petkas, P. J., \& Blackwell, K. (1972). Whistle Blowing: The report of the conference on professional responsibility. New York: Grossman.

Near, J. P., \& Miceli, M. P. (1995). Effective whistle-blowing. Academy of Management Review, 20 (3), 679-708.

Ohio Department of Higher Education (2014). [Table of 2014 institutional ratios and scores for colleges and universities.] FY2014 Audited financial statements. Retrieved from https://www.ohiohighered. org/sites/ohiohighered.org/files/uploads/financial/SB6/Ratios_FY14.pdf on Nov. 13, 2015.

Ohio Development Services Agency (2016). Economic overview, GDP. Retrieved from http:// development.ohio.gov/files/research/E1000.pdf on Nov. 15, 2015.

Ratley, J. D. (2014). Report to Nations on occupational fraud and abuse. Austin, TX: Association of Certified Fraud Examiners.

Rutherford, A., \& Rabovsky, T. (2014). Evaluating impacts of performance funding policies on student outcomes in higher education. The ANNALS of the American Academy of Political and Social Science, 655 (1), 185-208. 
Christopher R. SCHMIDT. State level mechanisms for learning from whistleblowing cases at institutions of higher education in the United States

OF MANAGEMENT

IN THE $21^{\text {st }}$ CENTURY

Vol. 11, No. 1,2016

Schmidt, C. R. (2015). Learning points from whistleblower claims against institutions of higher education. Problems of Management in the 21st Century, 10 (2), 110-120.

Schmidt, C. R., \& Farkas, F. (2015). Anonymous reporting 'whistleblowing' as a mechanisms to improve institutions of higher education: The case of Ohio, presented at the Ministry of Education and Science International Round Table at Kazakh National Technical University, Almaty, 2014. Almaty, Kazakhstan: Kazakh National Technical University.

Schmidt, C. R., \& Kiraly, A. (2015). Commonalities between US and Hungarian universities with regards to organizational development and controls against the moral hazards of administration. The Hungarian Journal of Marketing and Management, 2015 (12). Pecs, Hungary.

Tandberg, D. A., \& Hillman, N. W. (2014). State higher education performance funding: Data, outcomes, and policy implications. Journal of Education Finance, 39 (3), 222-243.

US Department of Education IPEDS database. (2013). Fall Enrollment. Retrieved from http://nces. ed.gov/ipeds/trendgenerator on Nov. 16, 2015.

Vandekerckhove, W. (2006). Whistleblowing and organizational social responsibility: A global assessment. Hampshire, England: Ashgate Publishing Ltd.

Weissman, J. (2014). The decline of newspapers hits a stunning milestone [Web log post]. Retrieved Apr. 22, 2015 (http://www.slate.com/blogs/moneybox/2014/04/28/decline_of_newspapers_hits_a_ milestone_print_revenue_is_lowest_since_1950.html).

Advised by Dana Egerova, University of West Bohemia, Czech Republic

Received: February 27, 2016

Accepted: June 05, 2016
Christopher R. Schmidt

Candidate for PhD Business Administration, Certified Internal Auditor and Certified Management Accountant, University of Pécs, Rákóczi út 80, H-7622 Pécs, Hungary.

E-mail: schmidt.christopher@pte.hu 